\title{
Is proximity to a food retail store associated with diet and BMI in Glasgow, Scotland?
}

Laura Macdonald ${ }^{1 *}$, Anne Ellaway ${ }^{1}$, Kylie Ball ${ }^{2}$ and Sally Macintyre ${ }^{1}$

\begin{abstract}
Background: Access to healthy food is often seen as a potentially important contributor to diet. Policy documents in many countries suggest that variations in access contribute to inequalities in diet and in health. Some studies, mostly in the USA, have found that proximity to food stores is associated with dietary patterns, body weight and socio-economic differences in diet and obesity, whilst others have found no such relationships. We aim to investigate whether proximity to food retail stores is associated with dietary patterns or Body Mass Index in Glasgow, a large city in the UK.

Methods: We mapped data from a 'Health and Well-Being Survey' $(n=991)$, and a list of food stores $(n=741)$ in Glasgow City, using ArcGIS, and undertook network analysis to find the distance from respondents' home addresses to the nearest fruit and vegetable store, small general store, and supermarket.

Results: We found few statistically significant associations between proximity to food retail outlets and diet or obesity, for unadjusted or adjusted models, or when stratifying by gender, car ownership or employment.

Conclusions: The findings suggest that in urban settings in the UK the distribution of retail food stores may not be a major influence on diet and weight, possibly because most urban residents have reasonable access to food stores.
\end{abstract}

\section{Background}

Access to healthy food is often seen as a potentially important contributor to a healthy diet. Policy documents in many countries suggest that lack of such access in certain areas is one explanation for inequalities in diet and in health [1,2]. A growing number of studies have explored links between the local food retail environment, and dietary habits or overweight/ obesity. Recent reviews report inconclusive results [3-7]. For example, a number of studies based in regions of the USA found that better supermarket access was associated with increased fruit and vegetable intake [8], and dietary quality $[9,10]$, and reduced levels of overweight/obesity [11-17]. Higher intakes of fruit and vegetables were seen amongst those with better access to large, non-chain grocery stores [18], and smaller food stores $[19,20]$, while a shorter distance to fruit and vegetable stores was associated with healthier

\footnotetext{
* Correspondence: laura@sphsu.mrc.ac.uk

'MRC/CSO Social \& Public Health Sciences Unit, 4 Lilybank Gardens,

Glasgow, G12 8RZ, Scotland, UK

Full list of author information is available at the end of the article
}

body mass index (BMI) [16]. On the other hand, in some studies, better access to supermarkets $[21,22]$, convenience stores $[14,15,17]$, and small grocery stores $[13,22]$ was associated with increased levels of overweight/obesity, while no significant links were found between supermarket proximity and fruit and vegetable intake [18], or between small grocers, convenience stores, and BMI [11].

Evidence from outside the USA about associations between neighbourhood environments and diet or obesity is also mixed. A New Zealand study found no association between fruit and vegetable intakes and better access to food stores, but living near a convenience store was negatively associated with vegetable intake [23], while a study in Australia found that supermarket density was not associated with fruit and vegetable intake [24]. In Japan there were no greater intakes of fruit and vegetables with better access to fruit and vegetable stores, grocery stores or supermarkets [25]. Several UK studies have found no links between supermarket proximity and fruit and vegetable intake [26] or levels of obesity [27]; however a recent study across the Republic
Ciomed Central

(c) 2011 Macdonald et al; licensee BioMed Central Ltd. This is an Open Access article distributed under the terms of the Creative Commons Attribution License (http://creativecommons.org/licenses/by/2.0), which permits unrestricted use, distribution, and reproduction in any medium, provided the original work is properly cited. 
of Ireland did find a link between nearness to a supermarket and better diet [28].

Given this observed variation across studies, there is a need for further investigation of the associations between retail food environments and both diet and body weight [29]. This is particularly important in countries outside of the USA, in the light of the relative dearth of international data, and evidence of systematic differences in food store distribution patterns between the USA and other countries. We have previously shown that, unlike in many cities in the USA, the distribution of various types of food retailer in Glasgow does not disadvantage poorer socio-economic groups [30-32]. In this paper we investigate whether proximity to various types of food stores is associated with dietary patterns and BMI. We also explore these relationships separately by gender as a number of studies have found gender differences in the relationship between the neighbourhood environment and health and health behaviours [22,33-36], and we have previously shown in Glasgow that $87 \%$ of female respondents, compared to $30 \%$ of males, reported doing most of the food shopping for their household [37]. We also examine these relationships separately by household car access and employment status, since these might be hypothesised to influence food purchasing patterns, and we might expect the association between neighbourhood food environments and diet/obesity to be stronger amongst those who spend more time in their neighbourhoods.

\section{Methods}

We capitalised on two existing datasets relating to Glasgow City, Scotland: a 'Health and Well-Being Survey' (HWB, 2002), conducted in 2002 by the Greater Glasgow Health Board (GGHB), and a list of food retailers in 2007 held as part of the Glasgow City Council Public Register of Food Premises.

The HWB sample was stratified proportionately by local authority and deprivation category (DEPCAT), with addresses selected randomly. Over two thirds (67\%) of individuals contacted took part in the study which led to 1802 face-to-face interviews with adults in the GGHB in 2002. Data were gathered on individuals' socio-demographic characteristics, health and health behaviours. Data were weighted to ensure that they were representative of the adult population in this area [38]. In this paper we used only Glasgow City respondents $(\mathrm{N}=$ 1149) since the list of food stores was for Glasgow City. We used two measures of diet: daily consumption of fruit and vegetables, and daily consumption of high-fat snacks, as these data were available within the survey and because these two key indicators of diet have been associated with obesity risk $[39,40]$. For fruit and vegetable consumption we created a variable of eating five or more portions of fruit and vegetables daily versus less than this, based on two questions ('On average, how many portions of fruit do you eat each day?', and 'On average how many portions of vegetables or salad (not counting potatoes) do you eat each day?'). The high-fat snack consumption variable was based on responses to the question 'How often PER DAY do you usually eat items such as cakes, pastries, chocolate, biscuits and crisps?', which we grouped into none or one versus at least two (we also explored a grouping of none versus one or more). The former categorisation (none or one versus at least two) was used by the GGHB within the HWB report [38]. BMI was calculated from self-reported height and weight measurements, from which we constructed a three-category variable ('healthy weight' 18.524.99, 'overweight' 25-29.99, 'obese' 30 and over) and also a two-category variable with a threshold of $<25 \mathrm{v}$ $25+$. Respondents who were underweight (BMI less than $18.5, \mathrm{~N}=37$ ) were excluded from the analysis. We used measures of household car ownership (household had access to one or more cars, or none) and of employment status (as a dichotomous variable, with those in fulltime employment, training or education categorised as 'employed' and those who were unemployed, permanently sick/disabled, retired or homemakers categorised as 'not employed'). Socio-economic position was represented by an occupationally based 'Socio-Economic Group' classification, which had been grouped into three categories ('A/B/C1', 'C2', 'D/E'). These socio-demographic variables were included since they might influence ease of access and proximity to food stores, and the amount of time spent in the local neighbourhood.

The list of food retailers $(n=741)$ was held by the Council for licensing, inspection and planning purposes, and included all premises that fall under the 1995 Food Safety and Hygiene guidelines [41]. We used the Council defined categories, 'supermarket' (which included large chain supermarkets and superstores, selling a wide range of food products $n=68$ ), 'general store' (which included smaller independent food stores and chain outlets, selling a smaller range of food products $n=637$ ), and fruit and vegetable stores $(n=36)$. We excluded other categories on the Council list such as delicatessens, butchers, fishmongers etc.

We obtained street maps (including point addresses) from the UK Ordnance Survey [42], and used ArcGIS version 9.1 software to geocode respondents and food retailers by their unit postcodes. We carried out network analysis (i.e. found the shortest path between two locations on a road network) to find the network distance in metres from each respondent to the nearest supermarket, general store and greengrocers.

Network distance to the nearest general store was dichotomised with a threshold of 500 metres, while 
network distance to the nearest fruit and vegetable store and nearest supermarket was dichotomised by 1000 metres. We chose 500 metres for the nearest general store to ensure the stores were local to the respondents, and because initial inspection of the data showed that application of a larger threshold for this variable resulted in too little variability (i.e. $98 \%$ of participants lived within 1000 metres of a general store). The 1000 metre threshold for the other stores represented an approximately 15 minute walk for adults in an urban area and this has been demonstrated as an appropriate distance in previous literature [28,43-47]. This threshold also produced a distribution suitable for analysis.

Logistic regression was used to explore associations between snack intake and distance to the nearest general store or supermarket; and between fruit and vegetable consumption and distance to the nearest fruit and vegetable store or supermarket. Multinomial regression was used to examine whether proximity to food retailers was associated with BMI category (using the three-category BMI outcome measure and also the two-fold variable). In addition we used GLM to explore whether proximity (as a continuous variable) was associated with diet and BMI as continuous outcome variables. We examined, firstly, unadjusted odds ratios for diet and BMI; secondly odds ratios adjusted for age, gender, and socio-economic position; and thirdly odds ratios adjusted for age, gender, socio-economic position, car ownership and employment status. We also formally explored various interactions within the models (e.g. age and gender; gender and employment status; gender and car ownership). We then conducted a stratified analysis by gender (controlling for age and socio-economic position), household car access (controlling for age, gender and socio-economic position), and employment status (controlling for age, gender and socio-economic position). Within the HWB survey 991 respondents had no missing values for any of the variables to be included in the analysis (see table 1 ).

\section{Results}

Almost three quarters (73\%) of the HWB sample lived within 500 metres $(\mathrm{m})$ of a general store, $32 \%$ within $1000 \mathrm{~m}$ of a fruit and vegetable store, and $46 \%$ within $1000 \mathrm{~m}$ of a supermarket.

We found few statistically significant associations between proximity to food outlets and diet or BMI.

Table 1 GGHB ‘Health and Well-Being Survey 2002’ Respondents ( $=991$ )

\begin{tabular}{|c|c|c|c|}
\hline & & $\mathrm{N}$ & $\%$ \\
\hline \multirow[t]{7}{*}{ Age category } & $16-24$ years old & 110 & 11.1 \\
\hline & 25-34 years old & 157 & 15.8 \\
\hline & $35-44$ years old & 165 & 16.6 \\
\hline & $45-54$ years old & 130 & 13.1 \\
\hline & $55-64$ years old & 120 & 12.1 \\
\hline & $65-74$ years old & 170 & 17.2 \\
\hline & $75+$ years old & 139 & 14.0 \\
\hline \multirow[t]{2}{*}{ Gender } & Male & 394 & 39.8 \\
\hline & Female & 597 & 60.2 \\
\hline \multirow[t]{3}{*}{ Socio-Economic Position } & $A, B, C 1$ & 346 & 34.9 \\
\hline & $\mathrm{C} 2$ & 225 & 22.7 \\
\hline & $D, E$ & 420 & 42.4 \\
\hline \multirow[t]{2}{*}{ Household owns a car } & Yes & 390 & 39.4 \\
\hline & No & 601 & 60.6 \\
\hline \multirow[t]{2}{*}{ Employment status } & Employed, full time student & 343 & 34.6 \\
\hline & Unemployed, retired, homemaker & 648 & 65.4 \\
\hline \multirow[t]{3}{*}{ Body Mass Index } & $18.5-24.99$ & 559 & 56.4 \\
\hline & $25-29.9$ & 310 & 31.3 \\
\hline & $30+$ & 122 & 12.3 \\
\hline \multirow[t]{2}{*}{ Fruit/vegetable consumption } & Less than 5 portions every day & 680 & 68.6 \\
\hline & At least five portions every day & 311 & 31.4 \\
\hline \multirow[t]{2}{*}{ High-fat snack consumption } & 2 or more high-fat snacks daily & 309 & 31.2 \\
\hline & 1 or less high-fat snack daily & 682 & 68.8 \\
\hline \multicolumn{4}{|l|}{ Access to... } \\
\hline General store (within 500 m) & & 723 & 73.0 \\
\hline Fruit/vegetable retailer (within 1000 m) & & 313 & 31.6 \\
\hline Supermarket (within 1000 m) & & 458 & 46.2 \\
\hline
\end{tabular}


There was little difference in fruit and vegetable consumption by proximity to fruit and vegetable stores, and although the odds of obesity appeared lower in those living within $1000 \mathrm{~m}$ of a fruit and vegetable store this difference was not statistically significant. Odds of eating more than one high-fat snack daily, eating less than five portions of fruit and vegetables daily, and obesity were higher among those within $1000 \mathrm{~m}$ of a supermarket but again these results were non-significant. The only association statistically significant at the $5 \%$ level was that between obesity and proximity to general stores after adjustment for age, gender and socio-economic position (see table 2) and after adjustment for age, gender, socio-economic position, car ownership and employment status (see table 3). Results were broadly similar when distance and dietary intake were used as continuous, rather than categorical, variables in the analyses, and when BMI was included as a twofold category (data not shown). Results were similar for the odds of daily consumption of any snacks (data not shown). We found no significant interactions between age and gender, or between gender and employment status, or gender and car ownership (data not shown).

In the stratified analysis, as with the analysis of the total sample, there were few statistically significant associations (see table 4). There were no significant findings for females and non-car owners. Males were significantly less likely to eat five portions of fruit and vegetables daily if they lived within $1000 \mathrm{~m}$ of a supermarket ( $\mathrm{p}<0.01)$. Car owners had significantly greater odds of snacking ( $\mathrm{p}<0.05)$, and of being obese $(\mathrm{p}<0.05)$, if they lived within $500 \mathrm{~m}$ of a general store. Employed respondents were more likely to be obese when living within $500 \mathrm{~m}$ of a general store $(\mathrm{p}<0.05)$, and less likely to be obese when living within $1000 \mathrm{~m}$ of a fruit and vegetable store $(\mathrm{p}<0.05)$, while the unemployed were more likely to be obese when living closer to a supermarket $(\mathrm{p}<0.05)$.

\section{Discussion}

There were few clear or significant associations between proximity to food outlets and diet or BMI, either within the overall sample or within subgroups (e.g. men or women, households without a car(s) or households with a car(s), non-employed or employed). We did find an association between proximity to a supermarket and not eating fruit and vegetables which is puzzling, given that we controlled for age, gender and socio-economic positions, all of which may be associated with fruit and vegetable consumption. It is possible that proximity to a supermarket is a marker of proximity to a range of destinations selling energy dense foods. Contrary to expectations, associations were stronger among men, car owners and those in employment, a finding which is also puzzling since most hypotheses are that females, those out of the labour market and those without access to a car are more likely to be sensitive to exposures in their immediate residential environment.

Methodological limitations include the use of selfreported height and weight to calculate BMI, which may underestimate the true prevalence of overweight and obesity. For example, the proportions of respondents overweight and obese in the Health and Well-being survey (31.3\% and $12.3 \%$ respectively) are considerably lower than the proportions in the Glasgow area obtained by direct measurements in the Scottish Health Survey 2003 (37.0\% and 23.4\%) [38]. However, we do not know of any evidence to suggest systematic biases in underreporting by proximity to food store, gender or deprivation which would affect our analysis.

Table 2 Odds of meeting dietary recommendations, being overweight/obese, by store proximity (controls - age, gender, SEP)

\begin{tabular}{|c|c|c|c|c|}
\hline & $\mathrm{N}$ & $\begin{array}{l}\text { General store within } 500 \mathrm{~m} \\
\text { Odds Ratio }(95 \% \mathrm{Cl})\end{array}$ & $\begin{array}{l}\text { Fruit \& vegetable store within } 1000 \mathrm{~m} \\
\text { Odds Ratio }(95 \% \mathrm{Cl})\end{array}$ & $\begin{array}{l}\text { Supermarket within } 1000 \mathrm{~m} \\
\text { Odds Ratio }(95 \% \mathrm{Cl})\end{array}$ \\
\hline ALL RESPONDENTS & 991 & & & \\
\hline \multicolumn{5}{|l|}{ Diet } \\
\hline \multicolumn{5}{|l|}{ Eats high-fat snacks $>1$ daily } \\
\hline no & 682 & 1.00 & & 1.00 \\
\hline yes & 309 & $1.24(0.90-1.70), p=0.190$ & & $1.13(0.86-1.49), p=0.385$ \\
\hline \multicolumn{5}{|l|}{ Eats fruit \& vegetables, $>5$ daily } \\
\hline yes & 457 & & 1.00 & 1.00 \\
\hline no & 534 & & $0.97(0.71-1.31), p=0.826$ & $1.28(0.97-1.71), p=0.086$ \\
\hline \multicolumn{5}{|l|}{$B M I$} \\
\hline $18.5-24.99$ & 559 & 1.00 & 1.00 & 1.00 \\
\hline $25-29.99$ & 310 & $1.13(0.82-1.56), p=0.444$ & $0.99(0.73-1.36), p=0.973$ & $1.04(0.78-1.39), p=0.786$ \\
\hline $30+$ & 122 & $1.74(1.06-2.85), p=0.028$ & $0.79(0.50-1.26), p=0.325$ & $1.35(0.89-2.03), p=0.153$ \\
\hline
\end{tabular}


Table 3 Odds of meeting dietary recommendations, being overweight/obese, by store proximity (controls - age, gender, SEP, car ownership, employment)

\begin{tabular}{|c|c|c|c|c|}
\hline & $\mathrm{N}$ & $\begin{array}{l}\text { General store within } 500 \mathrm{~m} \\
\text { Odds Ratio }(95 \% \mathrm{Cl})\end{array}$ & $\begin{array}{l}\text { Fruit \& vegetable store within } 1000 \mathrm{~m} \\
\text { Odds Ratio }(95 \% \mathrm{Cl})\end{array}$ & $\begin{array}{l}\text { Supermarket within } 1000 \mathrm{~m} \\
\text { Odds Ratio }(95 \% \mathrm{Cl})\end{array}$ \\
\hline ALL RESPONDENTS & 991 & & & \\
\hline \multicolumn{5}{|l|}{ Diet } \\
\hline \multicolumn{5}{|l|}{ Eats high-fat snacks $>1$ daily } \\
\hline no & 682 & 1.00 & & 1.00 \\
\hline yes & 309 & $1.22(0.88-1.68), p=0.229$ & & $1.12(0.85-1.48), p=0.413$ \\
\hline \multicolumn{5}{|l|}{ Eats fruit \& vegetables, $>5$ daily } \\
\hline yes & 457 & & 1.00 & 1.00 \\
\hline no & 534 & & $0.94(0.69-1.28) \cdot p=0.702$ & $1.20(0.92-1.56), p=0.189$ \\
\hline \multicolumn{5}{|l|}{ BMI } \\
\hline $18.5-24.99$ & 559 & 1.00 & 1.00 & 1.00 \\
\hline 25-29.99 & 310 & $1.15(0.83-1.58), p=0.405$ & $0.99(0.73-1.36), p=0.994$ & $1.05(0.78-1.40), p=0.755$ \\
\hline $30+$ & 122 & $1.80(1.09-2.96), p=0.021$ & $0.81(0.51-1.28), p=0.362$ & $1.37(0.91-2.07), p=0.136$ \\
\hline
\end{tabular}

The list of food stores was for 2007, five years after the HWB data collection. However a recent comparison of Council held list of stores available in 1997 and 2007 showed considerable consistency (even when a food store had closed, often another similar type was occupying the premises) (Cummins, personal communication), and verification on the ground in 2007 showed $88 \%$ of the 2007 list to be present and trading under the same name [48].

We recognise that residential proximity may not be the most important factor influencing food purchasing; however we did not have access to information on where people shop (they might use stores near their place of work or study, or near their child's school). A Canadian study highlighted the importance of investigating environmental influences outwith the local home neighbourhood; travel survey data and retail food store locations were used to create a measure of the types of stores to which participants were exposed while carrying out their daily activities [49]. It was found that people's 'foodscapes' differ whether one considers food environment exposures around the home or further afield and that these 'foodscapes' also differ by age and by income. In an earlier study conducted in Glasgow, we found that people with lower incomes were more likely to shop for basic foodstuffs in local shops than in shops further afield [37].

In this paper we did not cover accessibility, affordability, or quality of healthy food items within local shops, which might be more important for diet than proximity to a food store. A survey of all food shops within 9 Scottish areas found that healthy food accessibility was determined by the types of stores in an area and by the stores' stocking policy [50]. There was a consistently high level of availability in large and medium general stores [51], while availability in small general food stores depended on urbanicity or rurality [52]. In urban areas people who depended on small food stores had limited access to healthy foods, and their food would cost more, than if they used larger stores in their area [50]. We are pursuing similar issues using data on price and availability of a basket of foods in food stores in Glasgow, and their relationship to deprivation, and this will be reported in a separate paper.

Our results differed to those of the majority of USA studies; we did not observe that living closer to a supermarket was associated with increased fruit and vegetable intake, or with reduced levels of overweight/obesity, and did not find a link between proximity to a fruit and vegetable store and healthier BMI ([8,11-16]). In line with a study in Japan [25] we found that fruit and vegetable intake was not higher with better access to fruit and vegetable stores or supermarkets, and similarly in line with another UK study we found no link between supermarket proximity and respondents' levels of obesity [27].

\section{Conclusion}

Despite its limitations we believe this study has contributed to the limited UK literature on the potential effect of local food retail upon diet and levels of overweight/ obesity, and has extended existing studies by looking at various food types and food stores. Our overall finding of a lack of consistent associations highlights the importance of national context, i.e. that findings should not be extrapolated from, for example, urban USA to other countries with different patterns of urban dwelling and retail markets $[32,53]$. Our previous findings that supermarkets are more likely to be located in poorer areas of Glasgow further illustrate the importance of not overgeneralising from one society to another [30]. One major 
Table 4 Odds of meeting dietary recommendations, being overweight/obese, by store proximity, stratified by gender, car ownership, employment

\begin{tabular}{|c|c|c|c|c|}
\hline & $\mathrm{N}$ & $\begin{array}{l}\text { General store within } 500 \mathrm{~m} \\
\text { Odds Ratio }(95 \% \mathrm{Cl})\end{array}$ & $\begin{array}{l}\text { Fruit \& vegetable store within } 1000 \mathrm{~m} \\
\text { Odds Ratio }(95 \% \mathrm{Cl})\end{array}$ & $\begin{array}{l}\text { Supermarket within } 1000 \mathrm{~m} \\
\text { Odds Ratio }(95 \% \mathrm{Cl})\end{array}$ \\
\hline MALES & 394 & & & \\
\hline Diet & & & & \\
\hline \multicolumn{5}{|l|}{ Eats high-fat snacks $>1$ daily } \\
\hline no & 273 & 1.00 & & 1.00 \\
\hline yes & 121 & $1.35(0.83-2.19), p=0.232$ & & $1.14(0.73-1.78), p=0.567$ \\
\hline \multicolumn{5}{|l|}{ Eats fruit \& vegetables $>5$ daily } \\
\hline yes & 192 & & 1.00 & 1.00 \\
\hline no & 202 & & $0.85(0.53-1.38), p=0.517$ & $1.81(1.16-2.82), p=0.009$ \\
\hline \multicolumn{5}{|l|}{$B M I$} \\
\hline $18.5-24.99$ & 220 & 1.00 & 1.00 & 1.00 \\
\hline 25-29.99 & 142 & $1.21(0.76-1.93), p=0.414$ & $0.98(0.61-1.59), p=0.940$ & $0.80(0.52-1.24), p=0.322$ \\
\hline $30+$ & 32 & $1.86(0.77-4.46), p=0.166$ & $0.99(0.41-2.44), p=0.997$ & $1.24(0.57-2.70), p=0.580$ \\
\hline FEMALES & 597 & & & \\
\hline Diet & & & & \\
\hline \multicolumn{5}{|l|}{ Eats high-fat snacks $>1$ daily } \\
\hline no & 409 & 1.00 & & 1.00 \\
\hline yes & 188 & $1.21(0.79-1.85), p=0.378$ & & $1.14(0.80-1.64), p=0.462$ \\
\hline \multicolumn{5}{|c|}{ Eats fruit \& vegetables $>5$ daily } \\
\hline yes & 265 & & 1.00 & 1.00 \\
\hline no & 332 & & $1.02(0.68-1.53), p=0.920$ & $1.01(0.69-1.48), p=0.948$ \\
\hline \multicolumn{5}{|l|}{$B M I$} \\
\hline $18.5-24.99$ & 339 & 1.00 & 1.00 & 1.00 \\
\hline 25-29.99 & 168 & $1.02(0.65-1.60), p=0.926$ & $0.98(0.65-1.49), p=0.939$ & $1.28(0.86-1.89), p=0.220$ \\
\hline $30+$ & 90 & $1.81(0.99-3.34), p=0.055$ & $0.81(0.47-1.39), p=0.437$ & $1.47(0.90-2.41), p=0.122$ \\
\hline CAR OWNER & 390 & & & \\
\hline Diet & & & & \\
\hline \multicolumn{5}{|l|}{ Eats high-fat snacks $>1$ daily } \\
\hline no & 283 & 1.00 & & 1.00 \\
\hline yes & 107 & $1.76(1.04-2.99), p=0.035$ & & $0.80(0.50-1.28), p=0.347$ \\
\hline \multicolumn{5}{|l|}{ Eats fruit \& vegetables $>5$ daily } \\
\hline yes & 225 & & 1.00 & 1.00 \\
\hline no & 165 & & $0.94(0.60-1.48), p=0.802$ & $1.52(0.99-2.32), p=0.051$ \\
\hline \multicolumn{5}{|l|}{$B M I$} \\
\hline $18.5-24.99$ & 221 & 1.00 & 1.00 & 1.00 \\
\hline $25-29.99$ & 120 & $1.48(0.89-2.46), p=0.127$ & $0.71(0.42-1.19), p=0.188$ & $1.01(0.63-1.62), p=0.959$ \\
\hline $30+$ & 49 & $2.61(1.19-5.75), p=0.017$ & $0.79(0.36-1.72), p=0.545$ & $1.31(0.66-2.60), p=0.449$ \\
\hline & & & & continued onto next page \\
\hline NO CAR & 601 & & & \\
\hline Diet & & & & \\
\hline \multicolumn{5}{|l|}{ Eats high-fat snacks $>1$ daily } \\
\hline No & 399 & 1.00 & & 1.00 \\
\hline Yes & 202 & $0.96(0.64-1.45), p=0.853$ & & $1.32(0.93-1.89), p=0.118$ \\
\hline \multicolumn{5}{|l|}{ Eats fruit \& vegetables $>5$ daily } \\
\hline Yes & 232 & & 1.00 & 1.00 \\
\hline No & 369 & & $0.91(0.60-1.38), p=0.647$ & $1.06(0.71-1.58), p=0.765$ \\
\hline \multicolumn{5}{|l|}{$B M I$} \\
\hline $18.5-24.99$ & 338 & 1.00 & 1.00 & 1.00 \\
\hline 25-29.99 & 190 & $0.97(0.63-1.48), p=0.881$ & $1.21(0.81-1.79), p=0.350$ & $1.09(0.75-1.58), p=0.648$ \\
\hline $30+$ & 73 & $1.40(0.72-2.69), p=0.320$ & $0.88(0.49-1.56), p=0.658$ & $1.38(0.81-2.34) \cdot p=0.232$ \\
\hline
\end{tabular}


Table 4 Odds of meeting dietary recommendations, being overweight/obese, by store proximity, stratified by gender, car ownership, employment (Continued)

\begin{tabular}{|c|c|c|c|c|}
\hline EMPLOYED & 343 & & & \\
\hline Diet & & & & \\
\hline \multicolumn{5}{|l|}{ Eats high-fat snacks $>1$ daily } \\
\hline no & 242 & 1.00 & & 1.00 \\
\hline yes & 101 & $1.38(0.78-2.42), p=0.266$ & & $0.84(0.51-1.38), p=0.488$ \\
\hline \multicolumn{5}{|l|}{ Eats fruit \& vegetables $>5$ daily } \\
\hline yes & 197 & & 1.00 & 1.00 \\
\hline no & 146 & & $0.87(0.54-1.39), p=0.553$ & $1.30(0.83-2.05), p=0.256$ \\
\hline \multicolumn{5}{|l|}{$B M I$} \\
\hline $18.5-24.99$ & 214 & 1.00 & 1.00 & 1.00 \\
\hline $25-29.99$ & 96 & $1.02(0.59-1.77), p=0.933$ & $0.90(0.53-1.53), p=0.698$ & $0.81(0.49-1.35), p=0.424$ \\
\hline $30+$ & 33 & $3.07(1.08-8.77), p=0.036$ & $0.35(0.13-0.99), p=0.048$ & $0.90(0.40-2.01), p=0.787$ \\
\hline NOT EMPLOYED & 648 & & & \\
\hline \multicolumn{5}{|l|}{ Diet } \\
\hline \multicolumn{5}{|l|}{ Eats high-fat snacks $>1$ daily } \\
\hline no & 440 & 1.00 & & 1.00 \\
\hline yes & 208 & $1.14(0.77-1.68), p=0.517$ & & $1.28(0.91-1.80), p=0.150$ \\
\hline \multicolumn{5}{|l|}{ Eats fruit \& vegetables $>5$ daily } \\
\hline yes & 260 & & 1.00 & 1.00 \\
\hline no & 388 & & $0.91(0.68-1.21), p=0.519$ & $1.18(0.90-1.55) \cdot p=0.226$ \\
\hline \multicolumn{5}{|l|}{$B M I$} \\
\hline $18.5-24.99$ & 345 & 1.00 & 1.00 & 1.00 \\
\hline 25-29.99 & 214 & $1.17(0.78-1.74), p=0.453$ & $1.03(0.70-1.52), p=0.876$ & $1.16(0.81-1.65), p=0.423$ \\
\hline $30+$ & 89 & $1.45(0.82-2.57), p=0.198$ & $1.04(0.61-1.77), p=0.876$ & $1.64(1.01-2.67), p=0.045$ \\
\hline
\end{tabular}

feature of contemporary British cities may be that there is a sufficient spread and density of food retail stores such that no population groups are significantly disadvantaged in access to food (e.g. 98\% of HWB respondents lived within $1000 \mathrm{~m}$ of a general store, and $46 \%$ within $1000 \mathrm{~m}$ of a supermarket). In order to detect environmental determinants of food purchasing, diet and weight one might need to seek an environment with considerably more variation in food access than is observed in Glasgow.

Directions for further research might include exploring the healthiness and quality of what food retail outlets actually stock and promote in particular areas. It would also be useful to have access to actual consumer shopping behaviour, to ascertain what food people purchase, what shops and other food sources they use, and to understand the factors which influence food shopping. More sensitive comprehensive indicators of environmental exposures, such as 'foodscapes' or 'activity spaces' [49], would also be valuable.

\section{Acknowledgements}

LM, AE and SM are employed by the UK Medical Research Council. Kylie Ball is supported by an Australian National Health \& Medical Research Council Senior Research Fellowship, ID 479513. This work is part of the Neighbourhoods and Health Programme (MC_US_A540_0073) at the MRC/
CSO Social and Public Health Sciences Unit. We would like to thank Glasgow City Council for supplying the food outlet data and Greater Glasgow Health Board for supplying the survey data. We would also like to thank Geoff Der for statistical advice.

\section{Author details}

${ }^{1} \mathrm{MRC/CSO}$ Social \& Public Health Sciences Unit, 4 Lilybank Gardens, Glasgow, G12 8RZ, Scotland, UK. ${ }^{2}$ School of Exercise and Nutrition Sciences, Deakin University, 221 Burwood Highway, Burwood VIC 3125 Australia.

\section{Authors' contributions}

LM did the mapping, data analysis and the literature review. AE, KB and SM contributed to the conception of the paper and discussion of the analysis. All authors contributed to successive drafts of the paper. All authors read and approved the final draft. LM is guarantor.

\section{Competing interests}

The authors declare that they have no competing interests.

Received: 10 December 2010 Accepted: 10 June 2011

Published: 10 June 2011

\section{References}

1. Marmot M, Allen J, Goldblatt P, Boyce T, McNeish D, Grady M, Geddes I: Fair Society, Healthy Lives. The Marmot Review. London: University College London; 2010.

2. Moodie R, Daube M, Carnell K, Connors C, Larkin S, Roberts L, Segal L, Selvey L, Zimmet P: Australia: the healthiest country by 2020 National Preventative Health Strategy - the roadmap for action. Canberra: Australian Government Preventative Health Taskforce; 2009.

3. Brug J, Kremers S, Lenthe F, Ball K, Crawford D: Environmental determinants of healthy eating: in need of theory and evidence. Proceedings of the Nutrition Society 2008, 67:307-316. 
4. Feng J, Glass T, Curriero F, Stewart W, Schwartz B: The built environment and obesity: A systematic review of the epidemiologic evidence. Health \& Place 2010, 16:175-190

5. Kamphuis C, Giskes K, de Bruijn G, Wendel-Vos W, Brug J, van Lenthe F: Environmental determinants of fruit and vegetable consumption among adults: a systematic review. British Journal of Nutrition 2006, 96:620-635.

6. Larson N, Story M: A review of environmental influences on food choices. Annals of Behavioral Medicine 2009, 36:S56-73.

7. Papas M, Alberg A, Ewing R, Helzlsouer K, Gary T, Klassen A: The built environment and obesity. Epidemiologic Reviews 2007, 29:129-143.

8. Morland K, Wing S, Diez-Roux A: The contextual effect of the local food environment on residents' diets: the atherosclerosis risk in communities study. American Journal of Public Health 2002, 92:1761-1767.

9. Laraia B, Siega-Riz A, Kaufman J, Jones S: Proximity of supermarkets is positively associated with diet quality index for pregnancy. Preventive Medicine 2004, 39:869-875.

10. Moore L, Roux A, Nettleton J, Jacobs D: Associations of the local food environment with diet quality - A comparison of assessments based on surveys and geographic information systems. American Journal of Epidemiology 2008, 167:917-924.

11. Black J, Macinko J, Dixon L, Fryer G: Neighborhoods and obesity in New York City. Health \& Place 2010, 16:489-499.

12. Brown A, Vargas $R$, Ang A, Pebley A: The neighborhood food resource environment and the health of residents with chronic conditions. Journal of General Internal Medicine 2008, 23:1137-1144.

13. Morland K, Evenson K: Obesity prevalence and the local food environment. Health \& Place 2009, 15:491-495.

14. Morland K, Roux A, Wing S: Supermarkets, other food stores, and obesity - The atherosclerosis risk in communities study. American Journal of Preventive Medicine 2006, 30:333-339.

15. Powell L, Auld M, Chaloupka F, O'malley P, Johnston L: Associations between access to food stores and adolescent body mass index. American Journal of Preventive Medicine 2007, 33:S301-S307.

16. Rundle A, Neckerman K, Freeman L, Lovasi G, Purciel M, Quinn J, Richards C, Sircar N, Weiss C: Neighborhood Food Environment and Walkability Predict Obesity in New York City. Environmental Health Perspectives 2009, 117:442-447.

17. Raja S, Yin L, Roemmich J, Ma C, Epstein L, Yadav P, Ticoalu A: Food Environment, Built Environment, and Women's BMI: Evidence from Erie County, New York. Journal of Planning Education and Research 2010, 29:444-460.

18. Zenk S, Lachance L, Schulz A, Mentz G, Kannan S, Ridella W: Neighborhood Retail Food Environment and Fruit and Vegetable Intake in a Multiethnic Urban Population. American Journal of Health Promotion 2009, 23:255-264.

19. Bodor J, Rose D, Farley T, Swalm C, Scott S: Neighbourhood fruit and vegetable availability and consumption: the role of small food stores in an urban environment. Public Health Nutrition 2008, 11:413-420.

20. Rose D, Richards R: Food store access and household fruit and vegetable use among participants in the U.S. Food Stamp Program. Public Health Nutrition 2004, 7:1081-1088

21. Lopez R: Neighborhood risk factors for obesity. Obesity 2007, 15:2111-2119.

22. Wang M, Kim S, Gonzalez A, MacLeod K, Winkleby M: Socioeconomic and food-related physical characteristics of the neighbourhood environment are associated with body mass index. Journal of Epidemiology and Community Health 2007, 61:491-498.

23. Pearce J, Hiscock R, Blakely $T$, Witten $K$ : The contextual effects of neighbourhood access to supermarkets and convenience stores on individual fruit and vegetable consumption. Journal of Epidemiology and Community Health 2008, 62:198-201.

24. Ball K, Crawford D, Mishra G: Socio-economic inequalities in women's fruit and vegetable intakes: a multilevel study of individual, social and environmental mediators. Public Health Nutrition 2006, 9:623-630.

25. Murakami K, Sasaki S, Takahashi Y, Uenishi K: Neighborhood food store availability in relation to food intake in young Japanese women. Nutrition 2009, 25:640-646.

26. Pearson T, Russell J, Campbell M, Barker M: Do 'food deserts' influence fruit and vegetable consumption? - a cross-sectional study. Appetite 2005, 45:195-197.
27. Stafford M, Cummins S, Ellaway A, Sacker A, Wiggins R, Macintyre S: Pathways to obesity: Identifying local, modifiable determinants of physical activity and diet. Social Science \& Medicine 2007, 65:1882-1897.

28. Layte R, Harrington J, Sexton E, Perry I, Cullinan J, Lyons S: Irish exceptionalism? local food environments and dietary quality. Journal of Epidemiology and Community Health 2011, 65.

29. Jones A, Bentham G, Foster C, Hillsdon M, Panter J: Tackling Obesities: Future Choices - Obesogenic Environments - Evidence Review. London: Government Office for Science; 2007.

30. Cummins S, Macintyre S: The location of food stores in urban areas: a case study in Glasgow. British Food Journal 1999, 101:545-553.

31. Macdonald L, Ellaway A, Macintyre S: The food retail environment and area deprivation in Glasgow City. International Journal of Behavioural Nutrition and Physical Activity 2009, 6.

32. Macintyre S, Macdonald L, Ellaway A: Do poorer people have poorer access to local resources and facilities? The distribution of local resources by area deprivation in Glasgow, Scotland. Social Science \& Medicine 2008, 67:900-914.

33. Ellaway A, Macintyre S: Women in their place: gender and perceptions of neighbourhoods in the West of Scotland. In Geographies of Women's Health. Edited by: Dyck I, Davis N, McLafferty S. London: Routledge; 2001:265-281.

34. Ellaway A, Macintyre S: Are perceived neighbourhood problems associated with the likelihood of smoking? Journal of Epidemiology and Community Health 2009, 63:78-80.

35. Molinari $C$, Ahern $M$, Hendryx M: The relationship of community quality to the health of men and women. Social Science \& Medicine 1998, 47:1113-1120.

36. Stafford M, Cummins S, Macintyre S, Ellaway A, Marmot M: Gender differences in the associations between health and neighbourhood environment. Social Science \& Medicine 2005, 60:1681-1692.

37. Ellaway A, Macintyre S: Shopping for food in socially contrasting localities. British Food Journal 2000, 102:52-59.

38. Jones R, Borland E, Boyd A, Lorenzetti K, Scouller J, Carey L, Tannahill C: The Health and Well-being of the Greater Glasgow Population. Glasgow: NHS Greater Glasgow; 2003

39. Bes-Rastrollo M, Sanchez-Villegas A, Basterra-Gortari F, Nunez-Cordoba J, Toledo E, Serrano-Martinez M: Prospective study of self-reported usual snacking and weight gain in a Mediterranean cohort: The SUN project. Clinical Nutrition 2010, 29:323-330.

40. He K, Hu F, Colditz G, Manson J, Willett W, Liu S: Changes in intake of fruits and vegetables in relation to risk of obesity and weight gain among middle-aged women. International Journal of Obesity 2004, 28:1569-1574.

41. Food Safety and Hygiene guidelines. 1995 [http://archive.food.gov.uk] dept_health/archive/busguide/hygrc.htm].

42. OS MasterMap (CD-ROM).

43. Apparicio P, Cloutier M, Shearmur R: The case of Montréal's missing food deserts: Evaluation of accessibility to food supermarkets. International Journal of Health Geographics 2007, 6.

44. Smoyer-Tomic K, Spence J, Amrhein C: Food Deserts in the Prairies? Supermarket Accessibility and Neighborhood Need in Edmonton, Canada. The Professional Geographer 2006, 58:307-326.

45. Cerin E, Frank L, Sallis J, Saelens B, Conway T, Chapman J, Glanz K: From neighborhood design and food options to residents' weight status. Appetite 2011, 56:693-703.

46. Frank $L$, Andreson M, Schmid T: Obesity Relationships with Community Design, Physical Activity, and Time Spent in Cars. American Journal of Epidemiology 2004, 27:87-96.

47. White M, Bunting J, Williams L, Raybould S, Adamson A, Mathers J: Do Food Deserts exist? A multilevel geographical analysis of the relationship between retail food access, socio-economic position, and dietary intake. Newcastle upon Tyne: Food Standards Agency; 2004.

48. Cummins S, Macintyre S: Are secondary data sources on the neighbourhood food environment accurate? Case-study in Glasgow, UK. Preventive Medicine 2009, 49:527-528.

49. Kestens $Y$, Lebel A, Daniel M, Theriault M, Pampalon R: Using experienced activity spaces to measure foodscape exposure. Health \& Place 2010, 16:1094-1103. 
50. Dawson J, Marshall D, Taylor M, Cummins S, Sparks L, Anderson A: Accessing Healthy Food: A Sentinel Mapping Study of Healthy Food Retailing in Scotland. Aberdeen: Food Standards Agency; 2010.

51. Cummins S, Smith D, Aitken Z, Dawson J, Marshall D, Sparks L, Anderson A: Neighbourhood deprivation and the price and availability of fruit and vegetables in Scotland. Journal of Human Nutrition and Dietetics 2010, 23:494-501.

52. Smith D, Cummins S, Taylor M, Dawson J, Marshall D, Sparks L, Anderson A: Neighbourhood food environment and area deprivation: spatial accessibility to grocery stores selling fresh fruit and vegetables in urban and rural settings. International Journal of Epidemiology 2010, 39:277-284.

53. Cummins S, Macintyre S: Food environments and obesity neighbourhood or nation? International Journal of Epidemiology 2006, 35:100-104.

\section{Pre-publication history}

The pre-publication history for this paper can be accessed here: http://www.biomedcentral.com/1471-2458/11/464/prepub

doi:10.1186/1471-2458-11-464

Cite this article as: Macdonald et al: Is proximity to a food retail store associated with diet and BMI in Glasgow, Scotland? BMC Public Health 2011 11:464.

\section{Submit your next manuscript to BioMed Central} and take full advantage of:

- Convenient online submission

- Thorough peer review

- No space constraints or color figure charges

- Immediate publication on acceptance

- Inclusion in PubMed, CAS, Scopus and Google Scholar

- Research which is freely available for redistribution

Submit your manuscript at www.biomedcentral.com/submit 